\title{
Postgraduate medical specialty training for Botswana: A successful innovative partnership with South Africa
}

\author{
M Cox, ${ }^{1,2}$ BMed, FACEM, MIPH; J Masunge, ${ }^{2}$ MB ChB, DCH (SA), FCPaed (SA); O Nkomazana, ${ }^{2}$ MB ChB, FCOpth (SA), MSc, PhD
}

${ }^{1}$ Faculty of Medicine and School of Public Health, University of Sydney, Australia

${ }^{2}$ Faculty of Medicine, Sir Ketumile Masire Teaching Hospital, University of Botswana, Gaborone, Botswana

Corresponding author: M Cox (megan.cox@sydney.edu.au)

Background. Sub-Saharan Africa has a significant shortage of healthcare providers, and educational collaborations are recommended as one of the crucial steps to increase the medical workforce.

Objectives. To describe a successful innovative postgraduate medical specialisation programme involving two neighbouring African countries, Botswana and South Africa (SA).

Methods. After lengthy consultative processes, a postgraduate training programme was approved between the University of Botswana and the Colleges of Medicine of SA (CMSA). This programme utilised a 4-year Master of Medicine (MMed) curriculum for consecutive training and examinations in both countries. Extensive collaborations with government and regulatory bodies in both countries were required to facilitate the programme.

Results. Despite initial diverse challenges, the two countries continue to support the partnership, with 40 local doctors having graduated as medical specialists since 2014, and additional MMed programmes in development for Botswana.

Conclusions. The University of Botswana and CMSA partnership model is a novel and sustainable cross-border collaboration with significant benefits for both health systems and individual trainees. It is possible to have a successful and high-quality specialisation programme without all the resources in place by being innovative and leveraging external partnerships and collaborations. This partnership hopes to encourage other developing countries to explore similar associations.

Afr J Health Professions Educ 2020;12(2):53-55. https://doi.org/10.7196/AJHPE.2020.v12i2.1221

Botswana is a southern African middle-income country of 2.2 million people, with a stable economic and political profile. ${ }^{[1]}$ The first medical school in the country, at the University of Botswana (UB), was opened in August 2009 and, courageously, 5 months later in January 2010, postgraduate medical specialisation programmes were launched. This establishment of local postgraduate specialisation programmes was seen as imperative for UB medical graduates' career paths, encouraging continuing medical employment in Botswana and thus providing local medical specialist graduates to reduce the significant country-wide shortages. ${ }^{[2]}$

\section{Methods}

While establishing the UB medical school, Botswana's health system was recognised as not yet able to ensure complete and high-quality in-country training for all postgraduate specialty programmes. UB staff engaged in extensive benchmarking exercises for high-quality and locally relevant specialist training programmes by examining curriculums, duration of training, models of governance and relationships with health services and government departments. Programmes in the UK, Canada, USA, Australia, East Africa and South Africa (SA) (largest regional neighbour) were reviewed.

This benchmarking exercise highlighted SA's programme as the most appropriate owing to internationally recognised medical education standards, comparable disease profiles and cultural similarities. SA's Master of Medicine (MMed) programmes are well established postgraduate training programmes with clinical, academic and research requirements over a 4-year curriculum. SA doctors who wish to specialise join these programmes, enrol in SA academic institutions as postgraduate students and work as residents in clinical rotations at the major teaching hospitals. Educational and clinical progress are measured by performance in the first (primary) and final (fellowship) specialty written and oral examinations run by the relevant medical specialty college in conjunction with the Colleges of Medicine of SA (CMSA).

Many sub-Saharan countries and individual medical practitioners utilise SA for full postgraduate medical education, but UB suggested a novel hybrid partnership, where doctors from Botswana enrolled in the UB MMed programme and performed the CMSA's relevant medical speciality training in both countries consecutively. The following specialties introduced this hybrid arrangement: anaesthesia, emergency medicine, internal medicine, pathology and paediatrics. The departments of Family Medicine and Public Health had well-established relationships with SA medical institutions and greater numbers of local faculty, and therefore elected to deliver their entire programmes in Botswana, with academic assistance from SA. The clinical and public health training platforms in the country were considered adequate for successful training.

The five UB specialty training programmes that decided to adapt and use the SA 4-year specialty curriculums, including the CMSA examinations and a research dissertation to fit $\mathrm{UB}$ regulations, required their programmes to be endorsed by the UB medical faculty and UB senate. Representation was made at various SA academic medical institutions through the CMSA to allow UB MMed students to initiate training in Botswana and then continue training in SA in accredited centres.

UB MMed students would work, study and pass their primary CMSA examinations in Botswana over the first 2 years and then move to SA, 
functioning as supernumerary doctors, but receiving the same clinical and academic supervision as their SA counterparts. This pathway is demonstrated in Fig. 1. Working in SA allowed MMed students to receive exposure and training for $18-24$ months in many areas not yet available in Botswana, depending on the specialty, and sit for the CMSA fellowship examination.

All MMed programmes were open to Botswana citizens, as well as to noncitizens, on a full-time basis. Applicants were required to have completed medical training at a recognised medical school and have been in active clinical practice for at least 2 years, with financial sponsorship arranged before enrolment and confirmation of selection. Doctors who successfully completed all UB MMed academic, clinical and research requirements qualified for the MMed degree from UB and specialist registration with the Botswana Health Professions Council, but would not be registered as a specialist by the Health Professions Council of SA (HPCSA). This arrangement hoped to encourage the growth of specialist clinical practice in Botswana.

A large recruitment process by UB employed local and expatriate medical staff for the new medical school curriculum and work in newly developed teaching hospitals in Botswana. ${ }^{[3]}$ Recruitment was slow, and some specialties staff proved extremely difficult to recruit or retain; therefore, timing of postgraduate programmes planned and initiated at UB occurred in relation to the availability of recruited staff. ${ }^{[4]}$ Internal medicine and paediatrics were the first to start in January 2010, followed by anaesthesia, family medicine, public health and emergency medicine the following year. Anatomical pathology was the last programme to be introduced in January 2013.

UB MMed students' enrolment and graduation numbers are shown in Table 1.

\section{Results}

Significant challenges occurred early in the first 2 years. In 2012, various logistical, human resource and financial challenges at UB led to uncertainty in both the undergraduate and postgraduate programmes. By 2013, one of the postgraduate programmes collapsed and UB MMed students had left many of the training programmes. ${ }^{[4]}$ The departure of significant numbers of senior UB clinicians left overwhelming academic and clinical workloads for those remaining; most programmes decided to decrease or not have yearly intakes. Medical registration with the HPCSA was lengthier than expected, and UB MMed students were delayed longer than expected for official SA student visas. The Botswana Ministry of
Health sponsored most UB MMed students. On starting supernumerary training in SA, the students found their salaries reduced owing to a Botswana government policy. The temporary loss of young hospital-based trainee specialists led to an increased burden on the Botswana health system, and trainees moving to SA left behind their young families, adding to personal and economic burdens. The four hybrid programmes based on the 4-year SA curriculum required extensions by an additional $1-2$ years owing to all these challenges.

A breakthrough occurred in 2014, when the UB medical school celebrated the graduation of the country's first 33 locally trained doctors and the first UB paediatric MMed student successfully completed the CMSA fellowship examination while training in Cape Town. More UB MMed students completed SA fellowship examinations in internal medicine and paediatrics the following year. These high-profile successes spurred on the MMed students and their supervisors, leading to graduations every year since. To date, 40 specialists have graduated with an MMed degree from $\mathrm{UB}, 20$ of them using this novel hybrid programme that has led to many ongoing benefits.

\section{Benefits to Botswana}

The UB medical school adopted a teaching health system whereby UB medical students and academic staff are present in numerous health centres in Botswana, in this way increasing healthcare providers and improving healthcare at all levels. ${ }^{[3]} \mathrm{UB}$ MMed students work, train and

Table 1. University of Botswana MMed students' enrolment and graduation

\begin{tabular}{|c|c|c|}
\hline UB MMed programme & $\begin{array}{l}\text { Students enrolled } \\
\text { in training } \\
(2010-2018), n\end{array}$ & $\begin{array}{l}\text { Students who } \\
\text { graduated } \\
(2014-2018), n\end{array}$ \\
\hline Internal medicine & 33 & 6 \\
\hline Paediatrics & 39 & 12 \\
\hline Emergency medicine & 9 & 3 \\
\hline Anatomical pathology & 10 & 0 \\
\hline Anaesthesia* & 6 & 5 \\
\hline Family medicine $^{\dagger}$ & 32 & 10 \\
\hline Public health $^{\dagger}$ & 17 & 4 \\
\hline Total & 146 & 40 \\
\hline
\end{tabular}

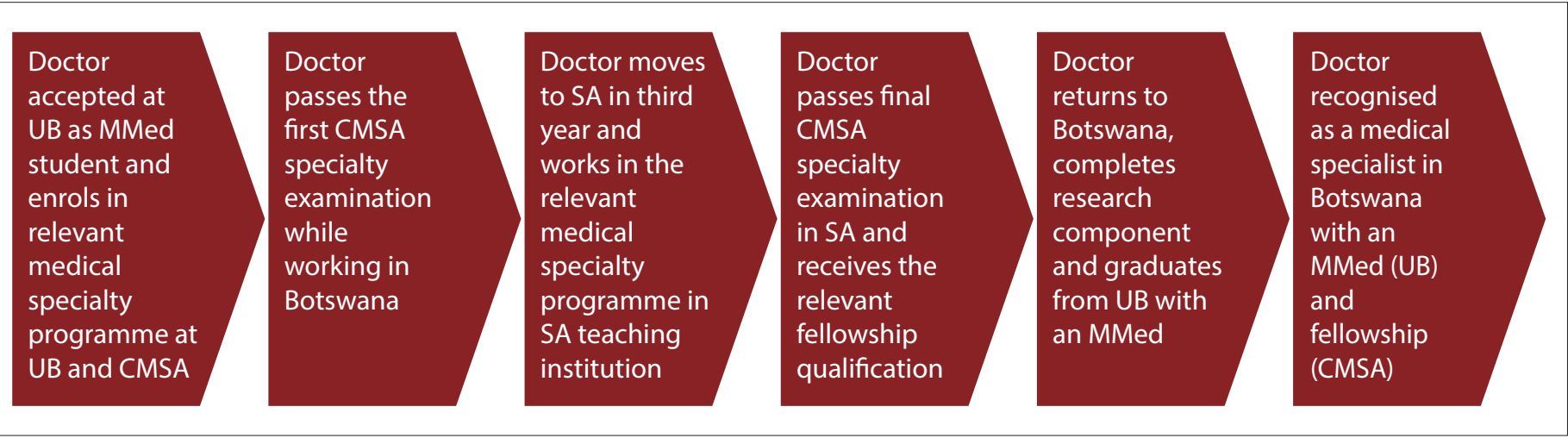

Fig. 1. Proposed hybrid pathway for UB/CMSA specialist training collaboration. (UB = University of Botswana; MMed = Master of Medicine; CMSA = Colleges of Medicine of South Africa; $S A=$ South Africa.) 
teach in this system, showcasing a locally based postgraduate programme for the many UB medical students who, in keeping with international trends, express an intent to specialise after graduation. ${ }^{[5]}$ For UB MMed students in SA, ongoing clinical supervision from SA specialists provided objective assessments of their clinical and academic progress for UB faculty. SA medical specialists also provided mentorship in educational support to UB medical faculty programmes through frequent curriculum and programme reviews. Relevant UB faculty were invited to assist with official CMSA examinations, improving their examination and academic development skills.

Progress is being made to match the duration of the UB MMed students curriculum with the SA 4-year curriculum. The research requirement was a major hurdle regarding the 4-year completion, as identified by UB faculty. UB faculty have been mentored in research principles, have been involved in local research partnerships and have established clearer guidelines and pathways for MMed research dissertations to be achieved earlier in the curriculum.

Leveraging on the successes and experiences of these existing MMed programmes, new UB postgraduate specialist medical programmes in psychiatry, surgery and obstetrics and gynaecology are being developed and hope to be ready in 2020. The increasing numbers of UB-trained specialists have not only improved the health system capacity but also increased the ability to train postgraduate specialists in Botswana. This progress envisages UB shortening some of the SA rotations and eventually fully localising some of the MMed programmes. Evaluations of all UB MMed programmes and postgraduation career pathways are planned.

\section{Benefits to South Africa}

UB MMed students and those from other countries live, train and work in SA on a supernumerary arrangement. They provide essential and muchneeded service at health institutions at no cost to the SA economy, and also participate in healthcare education to students and junior doctors at these institutions. This educational collaboration demonstrates that the SA medical education system accommodates variable levels of training residents, from those who do their entire training in SA, to those who spend a limited time in SA, such as the students in the hybrid arrangement with the UB MMed programme. The fact that the SA medical education system continues to complete this successfully over many years, indicates that they have significant expertise in various training needs. The adoption of the SA curriculum in Botswana raises the profile of SA medical specialisation programmes and promotes their healthcare system regionally and internationally.

\section{Conclusions}

The successful graduation of 40 local medical specialists since 2014, demonstrates that it is possible to have a successful and high-quality medical specialisation programme, without all the resources in place, by being innovative and leveraging external partnerships and local collaborations. Frequent consultations with government health and finance departments, medical specialist colleges and registration bodies in Botswana and SA were crucial for this productive health education and training partnership. The success of this novel hybrid specialisation programme and the benefits to both countries should encourage further networking and research between them, as well as inspire academic medical institutions in other developing countries to consider implementing similar partnerships.

\section{Declaration. None.}

Acknowledgements. The authors would like to acknowledge the assistance of the many staff from the Botswana Ministry of Health and University of Botswana, who were pivotal to the success of this partnership.

Author contributions. MC and JM wrote the article; all three authors edited the article and approved the final version.

Funding. None.

Conflicts of interest. None.

1. World Health Organization. WHO Country Statistics - Botswana. Geneva: WHO, 2019

2. Nkomazana O, Peersman W, Willcox M, Mash R, Phaladze N. Human resources for health in Botswan The results of in-country database and reports analysis. Afr J Prim Health Care Fam Med 2014;6(1):E1-E8 https://doi.org/10.4102/phcfm.v6i1.716

3. Mokone GG, Kebaetse M, Wright J, et al. Establishing a new medical school: Botswana’s experience. Acad Med 2014;89(80):S83-S87. https://doi.org/10.1097/ACM.0000000000000329

4. Kebaetse M, Mokone GG, Badlangana L, Mazhani L. Academic staff recruitment and retention challenges at the University of Botswana medical school. S Afr Med J 2016;106(7):730-734. https://doi.org/10.7196/SAMJ.2016 v106i7.10482

5. Rukewe A, Abebe WA, Fatiregun AA, Kgantshang M. Specialty preferences among medical students in Botswana BMC Res Notes 2017;10(1):195. https://doi.org/10.1186/s13104-017-2523-y 